
Design Model: Theoretical Review and Model Conceptualization 


\title{
Process-based Organization Design Model: Theoretical Review and Model Conceptualization
}

\author{
Tomislav Hernaus \\ thernaus@efzg.hr \\ Faculty of Economics and Business \\ University of Zagreb \\ Trg J. F. Kennedya 6 \\ 10000 Zagreb, Croatia
}

The views expressed in this working paper are those of the author(s) and not necessarily represent those of the Faculty of Economics and Business - Zagreb. The paper has not undergone formal review or approval. The paper is published to bring forth comments on research in progress before it appears in final form in an academic journal or elsewhere.

\section{Copyright 2008 by Tomislav Hernaus}

All rights reserved.

Sections of text may be quoted provided that full credit is given to the source. 


\begin{abstract}
The complexity of today's business world is translated into complexity of the company's organization design (Galbraith, 2002). Organizations are forced to quickly adapt to emerging complexity if they want to survive. The change is addressing all areas of business, especially questioning organizational effectiveness and trying to find optimal solutions for doing business.

In accordance with requirements, competitive trends are pushing executives to rethink traditional design configurations. Factors such as increased competition in cost, quality and service, and technical change have forced companies not only to seek out new ways of doing old tasks, but also new ways of organizing either old or new tasks (Cross, 1990). Such focus on the flow of work within organizations, but as well as between them, is emphasizing process orientation as a new management paradigm.

Inefficiencies of the two most commonly present structures - functional and divisional, in addition to emerging business trends, place the emphasis on a process-based organization as one of the possible solutions. The process-based organization is lead by the process paradigm, which is focused on the horizontal view of business activities and alignment of organizational systems towards business processes.
\end{abstract}

Regardless of a large interest on business processes, existing organization design theory offers only general guidelines for process-based organizations or more precisely, a process-based organization design model. Consequently, the purpose of the paper is to demystify process-based organization design model. By clearly distinguishing between different levels of process orientation, and by addressing characteristics of the chosen model the paper will lead to better understanding of this way of organizing. Eventually, an operationalized model of process-based organization is developed. Furthermore, the paper elaborates on differences between process-based and other organizational structures and philosophies (e.g. functional, product, matrix, project, team-based).

Besides structural elements, which will be in the primary focus, the paper will discuss the alignment of all other important organization design elements for process environment (e.g., management style, reward systems, performance metrics, people practices, organizational culture, etc.). There would be proposed necessary adjustments of organizational elements which should be aligned with the process-based structural solution. In such way, some of the blind spots of process-based organization design model would be revealed, providing practical implications for its implementation and ultimately, offering solution for rising business complexity.

\title{
Keywords
}

organization design, process-based organization, process-based organization design model, business processes

\section{JEL classification}

L22, M10, M15 


\section{Introduction}

The complexity of today's business world is translated into complexity of the company's organization design (Galbraith, 2002). Organizations are forced to quickly adapt to emerging complexity if they want to survive. The change is addressing all areas of business, especially questioning organizational effectiveness and trying to find optimal solutions for doing business.

In accordance with requirements, the competitive trends are causing executives to rethink traditional design configurations. Factors such as increased competition on cost, quality and service, and technical change have forced companies not only to seek out new ways of doing old tasks, but also new ways of organizing either old or new tasks (Cross, 1990). Such focus on the flow of work within organizations, but as well as between them, is emphasizing process orientation as a new management paradigm.

Currently, most organizational structures are based either on function or product, with little or no process orientation. Functionally organized companies have difficulty meeting customer needs seamlessly across different functions because no one "owns" the issue of how long it takes or how much it costs to fulfill customer requests (Davenport, 1995). The same works for divisionally organized companies, which are mostly oriented toward their products building market demand for those products they are able to produce, neglecting customer needs and their business relationships.

Inefficiencies of the two most commonly present structures, in addition to emerging business trends, place the emphasis on a process-based organization as one of the possible solutions. The process-based organization is lead by the process paradigm, which is focused on the horizontal view of business activities and alignment of organizational systems toward business processes.

The process paradigm or process orientation represents a broader term than process-based organization. While the former is a whole new way of thinking and new approach to doing business, the latter stands for applicative way of introducing higher levels of process maturity and process practice into companies. However, the idea of the process-based organization as a new organizational form, with the "business processes" as the basic organizational construct (Seltsikas, 2001) is gaining strong momentum. Even more, according to Levi (2002), it is becoming a mandatory requirement.

The idea of a process-based structuring is not new at all. Although some initiatives focusing on organizing work around business processes have been addressed earlier (e.g., Nordsieck, Henning, Chapple, Sayles) the increasing attention toward business processes was given by Quality movements (e.g., Total Quality Management, Lean Thinking, Six Sigma, etc.), and especially with Business Process Reengineering (BPR). Along with Hammer \& Champy (1993), Bryne (1993) among the first popularized the term "horizontal organization" and provided a prescriptive definition of a business process-oriented model (McCormack \& Johnson, 2001). Afterwards, many authors have studied the idea of organizing around business processes in a certain manner (Crosetto \& Macazaga, 2005; Davenport, 1993; Dutta \& Manzoni, 1999; Galbraith, 2002; Gardner, 2004; Groth, 1999; Harrington, 1991; Ostroff, 1999; Stalk \& Black, 1994).

Regardless of a large interest on business processes, existing organization design theory offers only general guidelines for process-based organizations or more precisely, a process-based organization design model. Although numerous approaches for the implementation of process-oriented elements exist, they are only partial. The literature on process-based companies is not extensive especially when it comes to setting up a process-based business unit or organization starting from process teams (Vanheverbeke \& Torremans, 1998). Furthermore, most of the related literature simply states the perceived advantages of business process management without sufficiently describing ways for the operational implementation of the approach (Becker, Kugeler \& Rosemann, 2003). There is also a lack of systematic view and in-depth studies of such kind of organizing.

In addition, there is an evidence of many unsuccessful BPR projects which staggered the process movement (e.g., Hammer, 1996; Trahant, Burke \& Koonce, 1997). All aforementioned caused that large proportion of authors and practitioners have gained wrong understanding of the process-based organization design model. Mere lack of clearness is confusing practitioners and academicians for a while. Moreover, there is even a dispute between experts on organization design about the usefulness of such way of organizing where some of them do not fully appreciate the central role of business processes (Spanyi, 2003).

Trying to answer previously addressed issues, the purpose of the paper is to demystify process-based organization design model. By clearly distinguishing between different levels of process orientation, and by addressing characteristics of the chosen model the paper will lead to better understanding of this way of 
organizing. Eventually, an operationalized model of process-based organization is developed. Furthermore, the paper elaborates on differences between process-based and other organizational structures and philosophies (e.g. functional, product, matrix, project, team-based).

Besides structural elements, which will be in the primary focus, the alignment of all other important organization design elements for process environment (e.g., management practice, performance metrics, reward systems, people competencies, career paths, organizational culture, etc.) will be discussed in the paper. Necessary adjustments of organizational elements will be proposed, which should be aligned with the processbased structural solution. In such way, some of the blind spots of process-based organization design model would be revealed, providing practical implications for its implementation and ultimately, offering solution for rising business complexity.

\section{Strategic Importance and Features of Process-based Organizational Practice}

In order to achieve the best possible results, it is important to choose structures that match defined objectives, the nature of the required processes, and the systems central to those processes (Groth, 1999). Necessary actions arise from strategy which is always the starting point in trying to define an operational model of the company.

Chandler (1962) was among the first who studied a relationship between strategy and structure. He said that structure follows strategy. Nowadays, an intermediate step is recognized as needed: What follows directly from strategy is a clear definition of the core business processes required to execute that strategy, and it is this definition that enables you to build the kind of organization necessary to support the strategy (Browning, 1993). In that way, a strategy should drive business process design and business process design should drive organization design (Spanyi, 2003). Ultimately, the consequential derivation of the design from the strategy of a company needs to be adapted to conform to both the organizational structure and the business processes in order to foster the new orientation (Becker, Kugeler \& Roseman, 2003).

Processes are intrinsic to any type of organizational designs. For instance, information and decision processes cut across the organizational structure. According to their role and purpose, the structure is thought of as the anatomy of the organization, while processes are its physiology or functioning (Galbraith, 2002). Moreover, it's the 'white space' on the organization chart, the term introduced by Rummler \& Brache (1995), and those handoffs between departments, that must be managed to optimize overall company performance from the customer's perspective (Spanyi, 2003). 'White space' is resulting from the lack of mutual adjustment between structure and processes in the organization. Logically, those two main organizational elements should be aligned, because a logical process-oriented restructuring also includes a redesign of the organizational structure, and vice versa. Ideally, the design of an organization structure should always be linked to process redesign because it makes no sense to base the structure on inefficient processes (Sadler, 2001), which is often the case because the process architecture and organizational structure are designed separately (Oden, 1999).

The organizational form, which is mostly addressing the alignment between structure and processes, is commonly referred to as a process-based organization. It recognizes the integrative and aligning nature of processes. Process-based organizations are different from traditional organizations in several key ways: (1) they design and manage end-to-end business processes rather than tasks, (2) they measure and manage processlevel results instead of departmental efficiency, and (3) they think in terms of customer goals instead of localized functional goals. The process-based organization offers a more powerful and complete paradigm for exploiting the power of process (Gardner, 2004).

The primary focus of process-based organization is on the horizontal dimension, which emphasizes the relationships between the functions. Such organizational form is more flexible, adaptive, and responsive than traditional ones. Furthermore, it handles changes better. By organizing around core business processes rather than functions, company establishes a more natural fit between work and structure than the traditional vertical structure can achieve (Vanheverbeke \& Torremans, 1998; Ostroff, 1999). It is a suitable way to overcome coordination problems and, ultimately, it delivers the value to a customer, representing a source of the competitive advantage for the company through shorter cycle times, higher product quality, etc.

Undoubtedly, a process-based organization is currently fashionable. However, there should be made a clear distinction between process-based organizations and some existing organizational forms which are similar 
to it (e.g., team-based organization, project or product organization, process-oriented functional organization, matrix organization).

Very often the process-based organization is perceived like a team-based organization. However, the team-based organization is a broader term and it represents an organizational philosophy rather than concrete organizational structure. The process-based organization is more formal than team-based, although the basic building blocks are the same - teams.

A project organization is temporary organizational form, present during the particular project lifecycle. Because projects are similar to processes in some characteristics, many authors and practitioners are confusing these two organizational forms. However, the basic difference is that a process is a permanent, repetitive activity, while each project is unique and unrepeatable.

A product organization or product organizational structure is organized around divisions - products. Each product division is a self-contained business unit, mostly oriented only on its own business, very often without cross-divisional understanding and lateral activities. As nowadays products are becoming integrated, divisional structures cannot respond adequately on customer requirements without necessary lateral integration. Customers more often want a whole service and/or package of different products which were historically done by separate divisions.

A functional organization is based on a different philosophy - it is organized around business functions, with strong vertical orientation. Shortcoming of the functional organization is that it inhibits process improvement because no organizational unit has control over a whole process, although many processes involve a large number of functions. However, a manufacturing function could be, and very often is, organized in process terms, according to natural work flow. But, that is only one department or part of the organization which is process-oriented, while other parts are still functionally 'constrained'. However, such organizations are called process-oriented functional organizations.

Finally, a matrix organization is emphasizing two dimensions of organizing at the same time. It is based on dual focus and dual responsibility (for instance, process and functional dimension). Although it offers structural alternative capable for handling more complex business practice by creating generalists, in such design model there are greater opportunities for conflict and higher levels of collaboration demanded (Davis \& Lawrence, 1977), unclear reporting relationships, and excessive time spent in coordination activities and meetings (Galbraith, 2002).

To avoid possible misunderstanding and misconceptions the process-based organization should be defined more thoroughly. In such an organization, business processes are the central point. From a processoriented perspective, outputs flow between processes, not between organizational units, since output measurement also relates to the process (Osterle, 1995). Such a different approach does not mean or require downsizing. Although the process-based organizations reduce bureaucracy and eliminate non-value added work, if properly conceived and implemented, they develop new roles for current and future employees as well as new processes that provide value to the customer and help support long-term success (Ostroff, 1999).

The most valuable strength of the process-based organization is that it can significantly increase the company's flexibility and respond to changes in customer needs because of the enhanced coordination. The structure directs everyone's attention toward the customer, which leads to greater customer satisfaction as well as improvements in productivity, speed, and efficiency. In addition, employees take a broader view of organizational goals rather than being focused on the goals of a single department because there are no boundaries between functional departments (Daft, 2006).

In the literature, and consequently in business practice, there are many examples how companies implemented the process-based organization design. Such companies like General Electric, Motorola, Barclays Bank, Quntum, Texas Instruments, Xerox, IBM, Duke Power and others designed their organizations to suit particular needs, developing hybrid structures appropriate in their context. What attracts most attention in practice concerning the process-based organization design is a message that it is really very important and useful organizational configuration, applicable in various companies with different backgrounds.

\section{Level Perspective of Process-based Organizations}

While a need for organizations to focus on their core business processes has been recognized, still only few organizations have explicitly focused on identifying their core business processes and redefining their 
businesses in terms of these core processes. The definition of these, and appropriate business process architecture, is a non-trivial, evolutionary procedure requiring a certain level of organizational maturity in process knowledge and awareness (Dutta \& Manzoni, 1999).

A scope and maturity of business process architecture and a nature of changes within processes varies within organizations. Process maturity recently appeared as a mainstream topic in the business process management literature. The concept is offered as a path to business improvement and success (McCormack, 2007). Its basic notion is that there are different levels of process orientation, and that companies should strive to reach higher process maturity levels. Although the process maturity will not be directly addressed in the paper, a level perspective will be studied more thoroughly.

It should be emphasized that, regarding the level perspective, when talking about business processes and its position in a company, a process hierarchy exists (e.g., process - subprocess - activity - task - step). Furthermore, there are different levels of potential process applicability, which are the following: across more than one company; at the enterprise level, such as over an entire corporation; across multiple business units within a corporation; within an individual business unit; over a core process group within a business unit; at the operating-unit level (say, a factory or office) within a business unit (Ostroff, 1999). Addressing specifically the process applicability issue, three common perspectives can be distinguished:

- Organizational level;

- Unit level;

- Individual level.

When speaking about business processes at the organizational level, they are embraced by process architecture. The process architecture determines how the organization can utilize the technology - what functions will be centralized or decentralized, and what are the connections between organizational units and the organization and its customers and suppliers (Oden, 1999). It gives an overview of the processes within the company, the most important processes of business partners, and the exchange of outputs between the processes (Osterle, 1995). The purpose of the process architecture is to define the basic physical building blocks of the company's processes in terms of what they do and what their common interfaces are.

At the unit level, process-oriented high-performance work systems that embody elements of total quality will tend to be the norm. These new designs are characterized by simplified business processes and work flows, advanced technological tools (expert systems, knowledge-based tools, smart documents), and innovative human system design (autonomous work teams, enriched job designs, flat hierarchies) (Nadler, Gerstein, Shaw et al, 1992). In many organizations, individual processes are often seen as separate units on an organization chart. However, managers need to view the organization as a whole and concentrate on the important organizational links among them, because changing any of them might have positive or negative impacts on the system as a whole (Evans \& Lindsay, 2005).

At the individual level, process orientation and business process practice have influence on job characteristics and people competencies. They shape job designs, accountabilities, and skill requirements - all of which significantly impact culture and competencies (Gardner, 2004). Jobs become more complex, broader and more challenging in process-based organizations, and employees have to be empowered as their work is more self-directing (Tomasko, 1993; Vanheverbeke \& Torremans, 1998). Individuals have broadened skills, including analytical and interpersonal skills, a commonality of language across the organization, an appreciation of each other's needs, and a better understanding of how things fit together (Johansson, McHugh, Pendlebury \& Wheeler III, 1993). A hierarchy in the process-based organization will be flattened throughout the organization by redesigning and restructuring roles and eliminating non-value-added work, by integrating work flows, and by vesting decision making at lower levels (Ostroff, 1999).

There are many alternatives how a company can be structured by business processes, because most processes consist of subprocesses. Some companies have identified as few as a half dozen major processes and other companies over a hundred. These differences are not necessarily a reflection of the relative complexity of the businesses but rather a function of the approach taken to identify the processes (Manganelli \& Klein, 1994). It represents only one source of vagueness. Other ones are related with the terminology and the understanding what a process-based organization really is.

Ghoshal and Bartlett (1997) do not particularly focus on process-based organizations but their view of management roles is completely in line with the requirements of a process-based company. They argue that companies have to change the behavioral context - the way individual organization members behave and act in order to remain vital. They no longer conceive viable companies in terms of their formal structures and 
organization charts, but as portfolios of core organizational processes that overlay and often dominate over vertical, authority-based processes of the hierarchical structure. From their standpoint, as well as from the discussion of others, a distinction could be drawn between companies according to the stage of process orientation.

Distinction between companies in an early stage of process orientation versus those in a later stage is very important and it has been made through the following terms: process-focused organization and processbased organization. One one hand, process-focused organizations are in an early stage in which process management is the responsibility of senior executives. On the other, process-based organizations are in a later stage in which process thinking has become more pervasive in the organization and the responsibilities for managing processes have been diffused throughout lower management levels (Brown \& Ross, 2003).

So forth, it became obvious that a process-based organization as a philosophy can stand for various levels of process orientation. Each particular level has its own rules of organizing, which are equivalent with their position at the process continuum. Accordingly to various process maturity stages, the following structural design options can be recognized:

- Functional structure;

- Functional structure with overlaid processes;

- Matrix structure;

- Process structure with functional overlays;

- Pure process structure.

Besides aforementioned structural options, some cross-functional process integration can be achieved by using lateral integrative mechanisms (Mintzberg, 1979, 1983; Galbraith, 1994; Daft, 2006; Jones, 2007). The benefits of a process orientation can be obtained by creating lateral process teams that coordinate across the functional structure, or just with establishing liaison roles, integrator roles or management positions.

However, multiple dimensions of a structure can help bridge the gaps created by a single structural dimension. But only when companies implement process-based organizational solutions processes will be managed in congruence with other aspects of the organization. Then, instead of cutting across the organization, process responsibilities will be a key focus of the organization (Davenport, 1993).

Processes cannot become the only basis for organizational structure because functional skills as well as product management remain important. Even more, not all activities can be aligned along processes, so that cross-process integration would be necessary in a purely process-based organization (Vanhaverbeke \& Torremans, 1998).

Most companies that have undertaken substantial process innovation initiatives have simply imposed process management as an additional dimension of structure - on top of the existing dimensions - assigning process ownership to managers who may also have functional and/or product responsibilities. In almost none of these companies process responsibility has been accorded organizational legitimacy (Davenport, 1993). That leads to a conclusion that the process orientation is necessary, but not always requiring a breakthrough change leading to process-based organization design.

A contingency approach towards process-based organization model is needed in different organizations. Most horizontal organizations will probably be hybrids, drawing the best from both the vertical and the horizontal, and combining performance capabilities of each (Ostroff, 1999). Note, however, that even in those organizations that become almost purely horizontal, some functional areas of competency will often remain necessary, and some organization-wide "vertical" management processes - such as strategic planning, finance, and human resources - must be retained to integrate the efforts of the horizontal operating processes and process groups.

\section{Conceptualization of Process-based Organization Design Model}

Identifying and defining possible structural options for process-based organization represents an important, first step toward conceptualization of process-based organization design model. When proposing a model, it should be clear what the model is about. According to Stanford (2007), model can be defined as:

- An image or framework that presents a template for guidance; or

- A representation of a set of components of a process, system, or subject area, generally developed for understanding, analysis, improvement, and/or replacement of the process; or 
- A representation of information, activities, relationships, and constraints.

Without a model it is hard to describe or think about an organization in a holistic way. However, one should be cautious and avoid often pitfalls of focusing only on the structure, disregarding the necessary alignment of all important organization design elements.

Each model should be theoretically underpinned, with logical reasoning and arguments which could verify it. Two precursors of the proposed model are those of Harrington and Harrington, who defined two different models of network organizational structure, and Dutta \& Manzoni (1999), who developed the knowledge-process model.

In their book Total Improvement Management, quality experts Harrington \& Harrington (1994) raised two different models of what they termed network organizational structures, which was apparently a wrong name. The second type of network organization they acknowledged was the horizontal process management structure. In that structure, the functional departments would still exist as the first dimension, while the second dimension is the process dimension. According to these authors, the organization would create process owners who are responsible for core processes. The point has made that, in horizontal process management structure, an employee's solid line reporting would be to the process head, while the functional head would have a dotted line relationship. However, this is not necessary for the process management organization to function (Chang, 2006).

Aimed to further refine and clarify the roles of business functions and process teams, some organizations are experimenting with another organizational form, which has been labeled a knowledgeprocess model. The knowledge-process model recognizes the need for both functional homes and crossfunctional process teams and thus explicitly acknowledges the dual needs of an organization: the need to create knowledge and the need to create value for customers by utilizing this knowledge within customer-oriented processes. Functions are assigned for a job of developing knowledge, while process teams are responsible for creating value for customers (Dutta \& Manzoni, 1999). The knowledge-process model moves responsibility for the execution of value-creating tasks solely to the process teams. The functions become almost like 'schools' assigned with two major responsibilities: (1) summarizing current knowledge, searching for new knowledge, and transfering knowledge to all their members; and (2) developing guidelines or best practices for utilizing the knowledge within value creating processes.

A process-based organization design model has been developed on the basis of aforementioned models, as well as other insights and experiences. The new process-based organization structure, therefore, must be one that is built by using the core processes and process teams as the foundation. Staff units (or support layers), centers of excellence (or pools of experts) or management positions in the hierarchy can be added to two main building blocks, but only if those add-ins create value by supporting process teams, and ultimately, by creating value for customers. Layers of management, groups, or individuals that do not provide value should not become part of the structure. This only increases costs and will lead to a common problem in organizations today, which is information overload (Oden, 1999).

Setting up a process-based organization always starts with the identification of the core processes of the company. After identifying core business processes, a hierarchy should be determined. In the process-based organization, the hierarchy is reduced, departmental boundaries are eliminated, and the organization is run by multidisciplinary process teams.

Organizational support systems are part of the organizational infrastructure that facilitates carrying out the processes necessary to do the work; to manage, control, coordinate, and improve it; and to manage the people who are doing it (Mohrman, Cohen \& Mohrman, 1995). These systems must support the way how work is conducted in the organization and must fit in the way the organization is designed. With changes in a design of organizations and with different ways of conducting work, the support systems must change to fit into the new logic as well.

In order to adequately satisfy emerging business needs, the process-based organizational structure should consist of: (1) few core business processes managed by process owners, who have direct support of process advisors; (2) centers of excellence, where the functional knowledge is gathered, with a role of connecting employees from similar functional areas (e.g., manufacturing, R\&D, marketing, etc.); (3) staff units or functional support units, in charge of administration and corporate activities (e.g., HRM, accounting, IT, legal affairs, public relations, etc.); and (4) a process council, which is responsible for lateral coordination between different processes and units. Proposed elements of the process-based organizational structure are somewhat similar to Mintzberg's organizational parts: operating core (operational workers); strategic apex (top 
management); middle line (middle managers); tehnostructure (technical experts); support staff (provide support to the organization outside its operating work flow). Especially important is to emphasize and clarify a distinction between the technostructure (centers of excellence) and support staff (staff units). While employees in staff units represent unique, formal organizational units, centers of excellence have more conceptual nature, connecting people exclusively for the purpose of creating, gathering and distributing the knowledge.

Figure 1: Process-based Organizational Structure

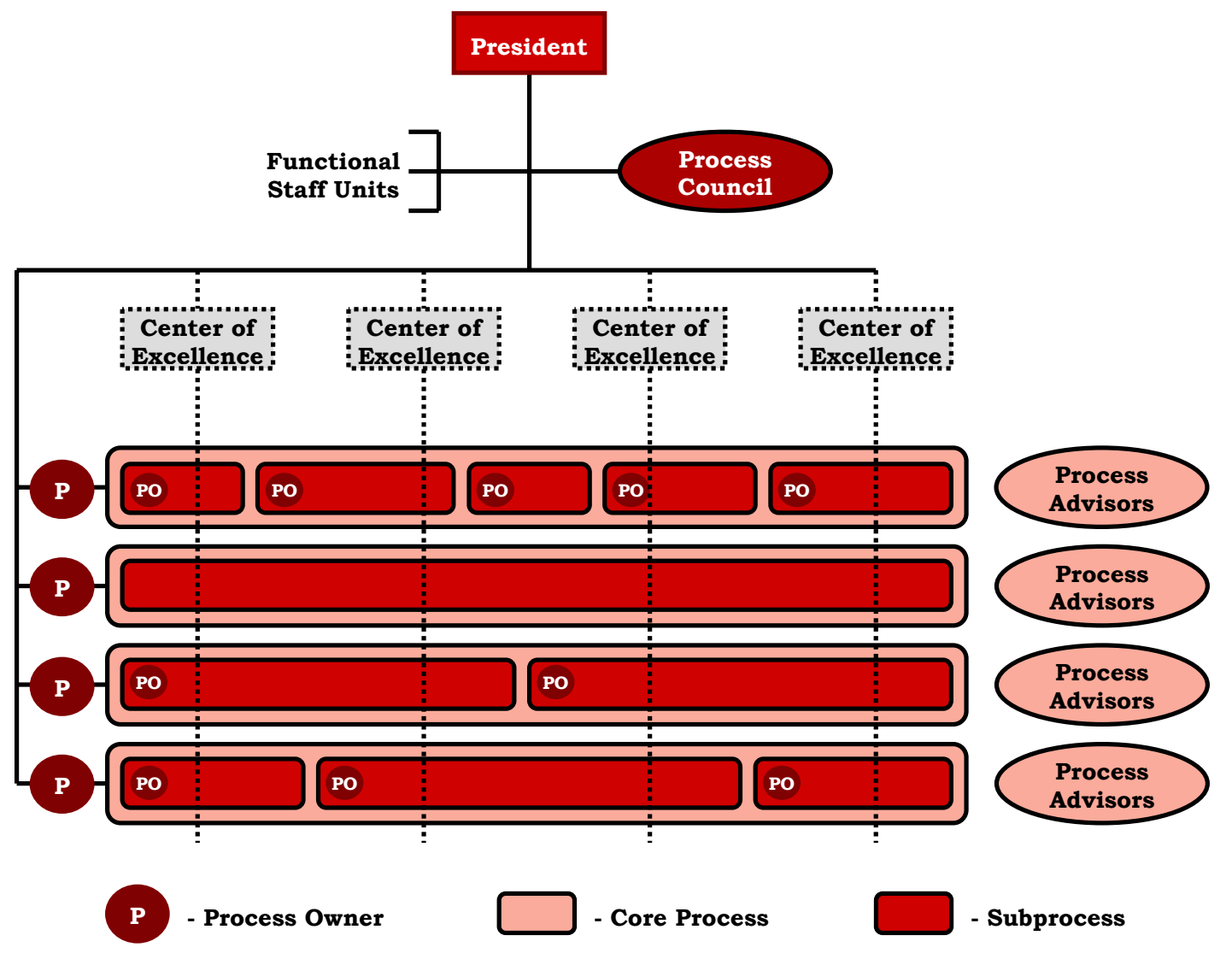

In addition to analyzing macro-organizational structure of the process-based design solution, more understanding is needed regarding the hierarchy of process roles and positions. The proposed model is developed for large companies, which are comprised from few key business processes and from large amount of subprocesses. However, distinction should be made between process owners - managers responsible for a particular core business process, and process managers, who are in charge and responsible for particular subprocess(es). Consequently, four hierarchical levels can be perceived in the organization, which is acceptable for large organizations. In the case of smaller organizations, roles of process owners and process managers are unified, which means that there is one hierarchical level less.

Hierarchical ladder of the process-based organization can be divided in three main levels: Board of Directors, Management, and Process Teams. Board of Directors, the governing body of an organization, has its Process council - advisory committee which discusses about process problems and process efficiency at the highest, strategic level. Vice-presidents are in charge of groups of core business processes as process sponsors, where they supervise execution of core business processes. Process sponsors and process owners have their own process advisors, who help them to understand the process execution of the processes in charge. Difference should be made between process advisors because there are process advisors who are reporting to the process sponsors with holistically oriented perspective of the group of key business processes, and those reporting to the process owners who are focused only on particular core business process and its subprocesses.

Second level, Management, is consisted of process and functional management. Regarding process management, process owners are established and they closely collaborate with functional managers, who are in 
charge of centers of excellence and staff units. Consequently, necessary resources for process execution are assured, as well as essential support for conducting key business activities.

Finally, third level consists of process teams, which represent the basic building block of the processbased organization. They are lead by process managers, who assure efficient execution of business processes.

Figure 2: The Hierarchy of Process Roles and Positions

\section{BOARD OF DIRECTORS}

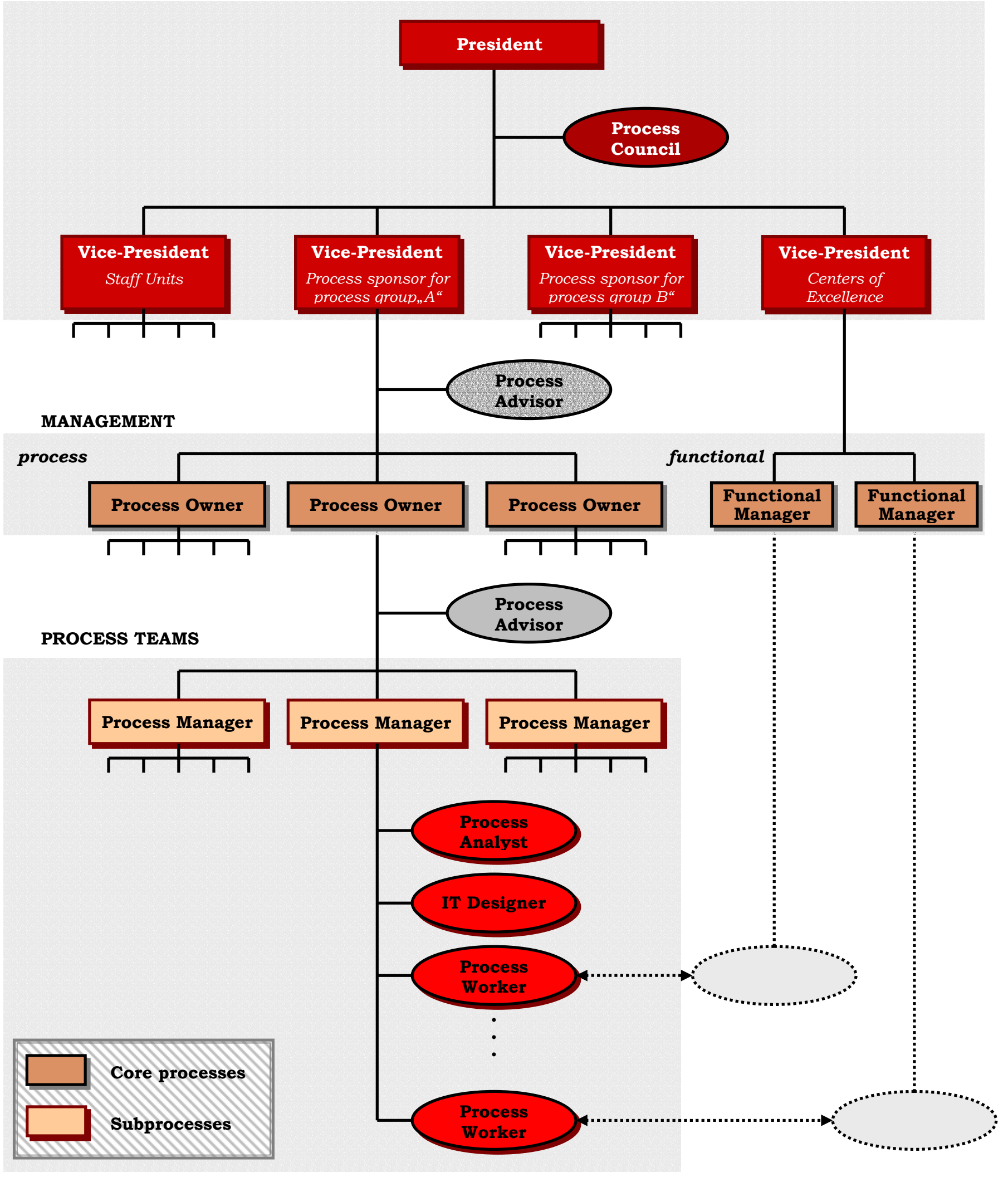




\section{Process Teams and Roles - Building Blocks of Process-based Organization}

The building blocks approach to organization is a concept mostly discussed by Meyer (2002). He argued that a building block has a unique perspective that contributes to the organization's overall balance of paradoxical objectives. Each organization design has its own specific building blocks. In a case of a processbased organization, two main building blocks, which should be addressed, are process teams and roles within those teams.

Process teams imply teams that are focused around a core business process, either to achieve the ongoing integration of its subprocesses and to make sure the business process is functioning as needed, or to improve the business process by redesigning it (Mohrman, Cohen \& Mohrman, 1995). Process teams should be busy $80 \%$ to $90 \%$ of their time with activities that belong to core business processes (Vanheverbeke \& Torremans, 1998). They can be formal or informal, although the first alternative is recommendable.

Process teams do not represent a group of job positions, but a group of work roles. The process roles most often present in process-based organizations are:

- Process sponsors or Process champions, who supervise a logical group of core business processes on the conceptual level of large and complex organizations;

- Process owners or Process stewards, who design core business processes, beam and enable process execution, plan, manage, and develop process activities, control its execution and performance, and adjust them according to the market requirements;

- Process managers, who plan, beam, and control defined group of processes and resources for creating expected outputs and business results;

- Process advisors or Process consultants, who are experts and possess knowledge about complete processes; they are providing process owners and process sponsors with advices and expertise, but they are also monitoring process efficiency and recommending process improvements;

- Process analysts, employees who have the widest knowledge about a particular business process and they are responsible for creating process documentation and modeling of AS-IS and TO-BE business processes;

- Process workers or Process leads, who are responsible for conducting specific tasks and activities in a particular business process;

- IT designers, who represent support staff to process analysts regarding IT questions.

As already mentioned, process owners' and process managers' roles are typically unified, or the process manager can report to the process owner. Process workers are responsible to the process manager, and they have a responsibility for activities which they perform, although some of them can be outsourced as well.

Prerequisite for successful implementation of process approach is placing capable, respectable managers in process owner's roles. By naming the most competent employees on those positions, management emphasizes high priority given to process dimension and seriousness of the process owner's role (Hammer \& Stanton, 2001). The process owner is the lowest-level manager responsible for the entire process. However, this does not necessarily mean that all of the employees involved in the process report to the process owner. What this does mean is that one manager is responsible and accountable for the process; that manager's performance evaluation and incentive compensation depend on the success of the process. The process owner is expected to negotiate with and coordinate with the managers with whose domain the process interferes (Oden, 1999).

If new position of the process owner and traditional position of the functional manager is not handled by the same manager, there is a potential for conflicts. For instance, in most companies which tried to impose some process elements, functional managers control resources, people, define priorities and make decisions. So, process owners do not possess control, they can just strive to shape business practice by using informal influence and power. To avoid conflicts between functional and process managers, both sides should be permissive, especially process owners who should:

- Try to understand priorities of functional managers;

- Offer feedback about process performance measurements;

- Discuss together with functional managers about problems, priorities and resources;

- Provide help to functional managers as needed;

- Constantly communicate with functional managers (Madison, 2005). 
Exactly because aforementioned tensions, process sponsor roles are established so that managers at the higher level can be moderators between functional and process managers. Although process sponsors would devote only part of their working time on business processes, they are appointing process owners and/or process managers who will be devoted to business processes and process improvement on the full-time basis (Tenner \& DeToro, 1996).

A process advisor or consultant's role is to monitor the performance of a process and continually improve it. This is accomplished by using measurements and feedback. Typical measurements include quality, timeliness, customer satisfaction, and cost. The process advisor should keep a process dashboard of key indicators and regularly share them with everyone who works in the process. This dashboard could also be prominently displayed for all to see (Madison, 2005).

Besides the process sponsor and the process owner, a process analyst has a key role in a process team. The process analyst represents an important member of the process team - expert for a business process design. His/her job is more of organizational than IT nature, and includes process documentation, process modeling, process analysis, and continuous process improvement activities (Khan, 2004). Although process analysts have the widest knowledge about particular processes, they do not have contact with value chains - integrative level of business processes at the higher level. Congruently, they often ignore the difference between core and support activities by focusing only on specific activities inside a particular process and conducting its analysis (Harmon, 2005).

In general, a process-based organization should attempt to have performed as many of traditional management functions as possible are performed by process team members or by introduced lateral integrative mechanisms, rather than by higher-ranked managers. In that sense, when there is more employees oriented towards business processes, the process paradigm has a better chance of surviving in the organization.

However, in practice employees usually belong both to process teams and to functionally based units (also known as "centers of excellence"). These employees, if there is no clear distinction of responsibility, and no primary dimension specified, are torned between two different philosophies. Such matrix positions are ungrateful and should be avoided. More common is a dual practice, which means that some employees simply are not members of process teams. It is legitimate and quite usual practice. In most cases, those are experts in some functional area, or process specialists (like process advisors) with staff authority, and who offer support service to the line units.

\section{Organizational Alignment for Process Environment}

Setting up a process-based organization is a major challenge because of difficulties of its implementation in a right way. Majchrzak and Wang (1996) have shown that simply changing organizational structure from functional units into process-based departments is not enough to guarantee improved performance. Tomasko (1993) also stated that creating a properly shaped process-based organization structure is vital, but it is not sufficient itself.

The process-based organization addresses the alignment challenge by first aligning the core business processes to enterprise goals and strategies, and then aligning the apparatus of the organization (structures, systems, and resources) to meet process needs (Gardner, 2004). In another words, the organization and its proposed structure should be put in a process environment. To achieve that, many changes are required. Necessary changes are described by Hammer:

- Work units change from functional departments to process teams.

- Jobs change from simple tasks to multi-dimensional work.

- People's roles change from controlled to empowered.

- Job preparation changes from training to education.

- Focus of performance measures and compensation shifts from activity to results.

- Advancement criteria change from performance to ability.

- Values change from protective to productive.

- Managers change from supervisors to coaches.

- Organizations change from hierarchical to flat.

- Executives change from scorekeepers to leaders (McCormack \& Johnson, 2001). 
Aforementioned are only several aspects of the required changes. They could be systematized according the following key organization design elements: (1) Management practice; (2) Performance management system; (3) Reward systems; (4) People competencies; (5) Career paths; (6) Organizational culture.

Implementing process concepts within organizations is only one step toward achieving a corporate process focus. In order to reap ongoing benefits from a process-based organization, continuous maintenance and control of the business processes is required. Process management deals with the efficient and effective execution of business processes. It consists of the planning, implementation, enactment and controlling of processes, and forms a life-cycle that leads to continuous process improvement. Process management addresses the requirement of companies to stay adaptable to environmental and internal changes (zur Muehlen, 2002). Furthermore, top and middle management in a process-based organization is much more supportive; it basically stimulates frontline entrepreneurship and integrates dispersed knowledge and best practices across business units. This new role of the different management levels allows a company to be more responsiveness to new competitive requirements that may quickly change in complex and dynamic environments. In this way process-based companies may have stronger dynamic capabilities than traditionally structured companies (Vanheverbeke \& Torremans, 1998).

Most organizations only have some of their processes well defined and are only beginning to use process measures and process management techniques to control their organizations (Harmon, 2003). Most organizations rely on departmental or functional goals and measures. They may talk process, but they measure silo-oriented results.

Organizations are beginning to implement performance management systems that reflect the new shape of the organization and its emphasis on integration of work, multi-directional influence, and flexible jobs that reflect competencies (Mohrman, Mohrman, and Lawler, 1992). These include new appraisal systems (peer appraisal; 360 degree systems that collect input from peers, managers, subordinates and customers; and team appraisals) and new reward systems (skill-based pay; team bonuses; gainsharing; and multi-level rewards based on individual, team and organizational level performance).

Executives should be compensated for process success. They should identify reward systems among aforementioned which would focus on the complete process and the satisfaction of customers, not narrow functional goals. In the best case, a company sets performance goals for value chains or business processes and then establishes an incentive program based on achieving those goals, apportioning rewards according to some formula that assures that each manager has an ongoing interest in the success of the overall process (Harmon, 2005a).

People's competencies are strongly influenced by the process architecture as well (Anupindi et al., 2006). Contrary to popular opinion, the process-based organization is not transforming employees to generalists (at least not all of them), who are capable of handling technical problems along the process execution (Ostroff, 1999). Such an impression is due to careful alignment of process team members with desire to cover all relevant areas of business. It emphasizes that integration of employees with specific skills and key competencies in cross-functional teams represents a special challenge. In the end, process teams or process departments are a complex mixture of generalists and specialists, who can be employed in various ways (Galbraith, Lawler III et al., 1993), where each individual is hierarchically positioned and valued according to his/her competencies and knowledge (Crosseto \& Macazaga, 2005).

Another important organization design element, which should be questioned, is a career path. Flatter hierarchy and less organizational levels are resulting in decreased opportunity for traditional promotion paths. Because there are less middle management positions, a process enterprise therefore needs to develop new career models that are not based on traditional hierarchical advancement. The solution could be a professional path, where individuals would be able to advance professionally according to the level of their knowledge and expertise, not only in a managerial hierarchy.

Finally, executives need to be confident with process-centric thinking before altering the organization's management structure and style. Before you start aligning your organization with your processes, appointing process owners or tying compensation to process performance, you need to ensure that your organization is ready for this cultural shift. The entire executive board should be confident that they are ready to take their organization in this direction (Lofts, 2002). A notion about a process culture has been introduced recently. An organization is said to be a Process Culture when business processes are naturally embedded in its thinking, lexicon, and decision-making. From creating new ideas to the ongoing work of 
improving current practices, processes are a natural part of thinking about how to make things work better. Importance of cultural adjustment is confirmed by Chang (2006), who argued that structural changes are not so useful if there is no culture which could support the process orientation.

\section{Conclusion}

Competitive trends are forcing companies to become more efficient each day. There is a very small number of companies which can afford themselves to function in a vacuum; others should optimize their business activities. Very useful way of reducing non-value added activities is a process orientation. It has been recognized by academicians, consultants, and practitioners as a management philosophy which can assure improved business practice.

Although process orientation has many concepts and ideas, one of the strongest initiatives is a processbased organization design. By structuring an organization around business processes, the process orientation would be characterized as very high priority level issue. To avoid unjustified fears, the process-based organization should be more explicitly and clearly defined and explained because in that way there would be better chances for its implementation.

Currently, a process-based organization was not clearly defined, leading to confusion and misunderstanding. The purpose of this paper was to clarify what this organization design model really stands for, what does it mean, and how the process-based organization should be organized. Besides very important structural questions, a necessary alignment of all other organization design elements has been emphasized. Without aligning the system as a whole, chances for a success would be minimal. Before the alignment process, general understanding should be achieved. According to Telem (1985), only a familiarity and understanding of the process-based organization, formal and informal organizational structures and interrelations between them, will enable us to understand the structure of the organization and the way it operates within the organizational space.

In almost every aspect of human life extremes are not welcomed. The same applies in business as well. For most of the companies the truth about a process orientation would be in the middle. By balancing an organization's functional and horizontal orientation and maintaining the balance needed between the vertical (functional hierarchy) and the horizontal (processes), they would be able to achieve the short- and long-term health of an organization.

Understanding of process orientation and current organizational position (which should be the starting point for latter refinement), is inadequate. Lack of empirical evidence is posing process ideas only as a good, sounding theory. But, for better understanding the concept should be investigated in practice more thoroughly. Theoretical foundations of the process-based organization design model are providing interesting background, but concrete empirical results should validate the theory, and provide more arguments for the process journey.

However, every horizontal organization is different which means that each organization, if it wants to create and deliver its value proposition, must devise its own, unique process-based organization design model, based on their core business processes. There are no organizations will have the same process-based organization design solution (despite surface similarities); just as no individuals have the same personality, history, and purposes (even though they may share the same name). However, there are some rules of thumb that should be obeyed. Main characteristics of the process-based organization should be applicable in any company.

Furthermore, this new organization design model should be present everywhere, in each particular organization, maybe not always as a major organizing practice, but at least as a remainder of the importance of lateral coordination, business process optimization and plenty of efficiencies which are offered by thinking about work through business processes. Its broad use is proposed because process-based concepts and tools are applicable to all companies, in the sense that they present global tools. However, each company is unique in terms of its organizational culture and the choice of its business strategy. Ultimately, the way in which you are going to build your company depends on which materials you have, as well as how prepared you are to manage the whole process. Without any of these requirements, you will be incapable of implementing new trends in organization design practice. 


\section{References}

1. Anupindi, R., Chopra, S., Deshmukh, S. D., Van Mieghem, J. A., Zemel, E. (2006), Managing Business Process Flows, Prentice Hall, New Jersey

2. Becker, J., Kugeler, M., Rosemann, M. (2003), Process Management: A Guide for the Design of Business Processes, Springer, Berlin

3. Brown, C. L., Ross, J. W. (2003), Designing a Process-Based IT Organization, Information Strategy: The Executive's Journal, Vol. 19 No. 4, pp. 35-41.

4. Browning, J. (1993), The Power of Process Redesign, McKinsey Quarterly, No. 1, pp. 47-58.

5. Byrne, J. A. (1993), The Horizontal Corporation, Business Week, No. 3351, pp. 76-81.

6. Chandler (1962), Strategy and Structure: Chapters in the History of the Industrial Enterprise, M.I.T. Press, Cambridge

7. Chang, J. F. (2006), Business Process Management Systems - Strategy and Implementation, Auerbach Publications, Boca Raton, Florida

8. Crosetto, G., Macazaga, J. (2005), The Process-Based Organization - A Natural Organization Strategy, HRD Press, Amherst

9. Daft, R. L. (2006), Organization Theory and Design, Thompson, Mason, Ohio

10. Davenport, T. H. (1993), Process Innovation: Reengineering Work through Information Technology, Harvard Business School Press, Boston

11. Davenport, T. H. (1995), Reengineering a Business Process, Harvard Business School Press, Boston

12. Davis, S. M., Lawrence, P. R. (1977), Matrix, Addison-Wesley, Reading

13. Dutta, S., Manzoni, J. F. (1999), Process Re-engineering, Organizational Change and Performance Improvement, McGraw-Hill, London

14. Evans, J. R., Lindsay, W. M. (2005), An Introduction to Six Sigma \& Process Improvement, SouthWestern College Pub, London

15. Galbraith, J. R. (1994), Competing with Flexible Lateral Organizations, Addison Wesley, Reading

16. Galbraith, J. R. (2002), Designing Organizations: An Executive Guide to Strategy, Structure, and Process, Jossey-Bass, San Francisco

17. Galbraith, J. R., Lawler III, E. E. et al.(1993), Organizing for the Future, Jossey-Bass Publishers, San Francisco

18. Gardner, R. A. (2004), The Process-Focused Organization, ASQ Quality Press, Milwaukee

19. Ghoshal, S. Bartlett, C. A. (1997), The Individualized Corporation, HarperBusiness, New York

20. Groth, L. (1999), Future Organizational Design - The Scope for the IT-based Enterprise, John Wiley \& Sons, Chichester

21. Hammer, M. (1996), Beyond Reengineering: How the Process-Centered Organization is Changing Our Lives, Harper Business, New York

22. Hammer, M., Champy, J. (1993), Reengineering the Corporation: A Manifesto for Business Revolution, HarperCollins Publishers, New York

23. Hammer, M., Stanton, S. (2001), How Process Enterprises Really Work, Harvard Business Review, Vol. 77 No. 6, pp. 108-118.

24. Harmon, P. (2003), Business Process Change: A Manager's Guide to Improving, Redesigning, and Automating Processes, Morgan Kaufmann Publishers, San Francisco

25. Harmon, P. (2005), BPM Governance, Business Process Trends, Vol. 3 No. 3, www.bptrends.com

26. Harmon, P. (2005a), Core, Management, and Enabling Processes, Business Process Trends, Vol. 3 No. 22, www.bptrends.com

27. Harrington, J. H. (1991), Business Process Improvement, McGraw-Hill, New York

28. Harrington, J. H., Harrington, J. S. (1994), Total Improvement Management, McGraw-Hill, New York

29. Johansson, H. J., McHugh, P., Pendlebury, A., Wheeler III, W. A. (1993), Business Process Reengineering - Breakpoint Strategies for Market Dominance, John Wiley \& Sons, New York

30. Jones, G. R. (2007), Organizational Theory, Design, and Change, Prentice Hall, New Jersey

31. Khan, R. (2004), Supporting BPM Teams, KMWorld, http://www.findarticles.com

32. Levi, M. H. (2002), The Business Process (Quiet) Revolution: Transformation to Process Organization, Interfacing Technologies Corporation, http://www.interfacing.com/rtecontent/document/CreatingProcess Organization03.pdf 
33. Lofts, N. (2002), Process Visualization: An Executive Guide to Business Process Design, John Wiley \& Sons, Ontario

34. Madison, D. (2005), Process Mapping, Process Improvement, and Process Management, Paton Press LCC, Chico

35. Majchrzak, A., Wang, Q. (1996), Breaking the Functional Mind-Set in Process Organizations, Harvard Business Review, Vol. 74 No. 5, pp. 93-99.

36. Manganelli, R. L., Klein, M. M. (1994), The Reengineering Handbook, AMACOM, New York

37. McCormack, K. P. (2007), Business Process Maturity: Theory and Application, DRK Research

38. McCormack, K. P., Johnson, W. C. (2001), Business Process Orientation - Gaining the E-Business Competitive Advantage, St. Lucie Press, Florida

39. Meyer, N. D. (2002), The Building Blocks Approach to Organization Charts, NDMA Publishing, Ridgefield

40. Mintzberg, H. (1979), Structuring the Organizations: A Synthesis of the Research, Prentice Hall, New Jersey

41. Mintzberg, H. (1983), Structure in Fives - Designing Effective Organizations, Prentice Hall, New Jersey

42. Mohrman, A. M., Mohrman, S. A. \& Lawler III, E. E., (1992), The Performance Management of Teams, In Bruns, W. (Ed.), Performance Measurement, Evaluation, and Incentives, Harvard Business School Press, Cambridge

43. Mohrman, S. A., Cohen, S. G., Mohrman, A. M. (1995), Designing Team-based Organizations - New Forms for Knowledge Work, Jossey-Bass, San Francisco

44. Nadler, D. A., Gerstein, M. S., Shaw, R. B. et al. (1992), Organizational Architecture: Designs for Changing Organizations, Jossey-Bass Publishers, San Francisco

45. Oden, H. W. (1999), Transforming the Organization: A Social-Technical Approach, Quorum books, Westport

46. Osterle, H. (1995), Business in the Information Age: Heading for New Processes, Springer, Berlin

47. Ostroff, F. (1999), The Horizontal Organization, Oxford University Press, New York

48. Rummler, G. A., Brache, A. P. (1995), Improving Performance: How to Manage the White Space on the Organization Chart, Jossey-Bass, San Francisco

49. Sadler, P. (2001), The Seamless Organization: Building the Company of Tomorrow, Kogan Page, London

50. Seltsikas, P. (2001), Organizing the Information Management Process in Process-Based Organizations, Proceedings of the 34th Hawaii International Conference on System Sciences

51. Spanyi, A. (2003), Business Process Management is a Team Sport, Anclote Press, Tampa

52. Stalk Jr., G., Black, J. E. (1994), The Myth of the Horizontal Organization, Canadian Business Review, Vol. 21 No. 4, pp. 26-29.

53. Stanford, N. (2007), Guide to Organisation Design, Profile Books, London

54. Telem, M. (1985), The Process Organizational Structure, Journal of Management Studies, Vol. 22 No. 1, pp. 38-52.

55. Tenner, A. R., DeToro, I. J. (1996), Process Redesign: The Implementation Guide for Managers, Prentice Hall, New Jersey

56. Tomasko, R. M. (1993), Rethinking the Corporation - The Architecture of Change, AMACOM, New York

57. Trahant, B., Burke, W. W., Koonce, R. (1997), 12 principles of organizational transformation, Management Review, Vol. 86 No. 8, pp. 17-21.

58. Vanheverbeke, W., Torremans, H. (1998), Organizational Structure in Process-based Organizations, Netherlands Institute of Business Organization and Strategy Research

59. zur Muehlen, M. (2002), Workflow-based Process Controlling, Logos Verlag, Berlin 